\title{
Globalization of the transport system of the agro- industrial complex in the conditions of modern society
}

\author{
M.A. Ananyev ${ }^{1 *}, Z$ Zh.Yu Bakaeva $^{2}$, O.L. Matveeva ${ }^{2}$, I.V. Steklova ${ }^{3}$, and E.N. Shchegoleva ${ }^{4}$ \\ ${ }^{1}$ Research Institute of food security OF Plekhanov Russian University of Economics, 115054, \\ Stremyanny lane, 28, Moscow, Russia \\ ${ }^{2}$ Department of accounting and electronic business of The Chuvash state University named after I. N. \\ Ulyanov, 428015, Moskovsky Prospect, 15, Cheboksary, Russia \\ ${ }^{3}$ Saratov state technical University named after Yuri Gagarin, 410054, Politechnicheskaya str., 77, \\ Saratov, Russia \\ ${ }^{4}$ Department of state municipal management and regional economy of The Chuvash state University \\ named after I. N. Ulyanov, 428015, Moskovsky Prospect, 15, Cheboksary, Russia
}

\begin{abstract}
The article deals with the problem of transportation of agricultural products. The main causes of problems in this area are identified. The mechanism of creating favorable conditions in the system of globalization relations of the modern economy is analyzed. The fundamental elements in the transport system are competition orientation and information ownership over a certain period of time. Globalization involves the integration of different types of transport systems at the sectoral characteristics. The purpose of the research is to study the essence, meaning and prospects of the concept of "economic transport space in the national food supply system" in the processes of food market globalization. The main indicators of the "economic space" are: first, to determine the parameters that characterize the economic transport space, and secondly, to determine the prospects for using its structural elements in the system of transport supply relations, depending on the temporal and spatial components in the modern sector of the economy to provide food for the needs of society.
\end{abstract}

\section{Introduction}

The urgency is due to the need for a paradigm shift in the strategy of development of food sector of the national economy in the context of globalization processes of the formation of the global food market and the formation of the priorities of the food system, the most important of which is the operation of the sector, large agricultural production. The strategy of priority development of the sector of large-scale agro-industrial production assumes that such companies will determine the profile of the" domestic sector of the agricultural economy and adequately represent Russia in foreign markets in the strategic future.. The

*Corresponding author: Ananev.MA@rea.ru 
purpose of the study is to strengthen the presence of the mechanism in the food market and clarify the parameters of management impact based on the justification of the main provisions of the regional agri-food policy. [1, P. 4637-4638].

\section{Materials and methods}

When identifying the main problems in the economic analysis of the agro-industrial complex at the macro level, the systematic approach of I. G. Lambert and L. Von bertalanfi is used. When analyzing economic processes at the micro-level, a comprehensive approach is used by V. M. Sorokin, V. L. Kokorenko, and V. A. Kutyrev, which is related to management. The basis of economic analysis is the work of P. Samuelson and I. Schumpeter, as well as the research of domestic analytical science by S. K. Tatur, S. B. Barngolts, M. I. Bakanov, and A.D. Sheremet.

In accordance with the above, we propose the following definition of the research object "economic transport space" - a set of material and technical objects that include the road network, represented by roads of various categories and having characteristics for its quality condition, as well as the economic mechanism for their use in economic practice (taxes, fees, etc.). This representation of the economic transport space is due to the need to understand the real processes in this area and solve the targets for the development of the national food supply system in the structure of information and logistics processes.

The range of globalization of the transport economy is ranked by levels: personal, interpersonal, local and national, international and global. Structuring transport systems in the structure of modern economic processes implies their further globalization. The model of transport processes in the economy is represented by their globalization in the context of ideas of their integration in reality, and the goal of which is focused on the future. The characteristics of economic space globalization include the worldwide spread of modern technologies in agriculture, which is defined by a "world without borders", and the creation of networks of all the world's economies, contributing to closer functional integration. Functional integration involves the division of functions in the transport sector into various executable concepts within this structural component. This can characterize both water and surface transport both separately and in its unity. The globalization of transport in the agroindustrial complex in modern society is characterized by the introduction of a single denominator for determining the time frame and ways of using certain raw materials and products for transportation. The definition of agricultural products that require transportation implies economic interests and the possibility of their consumption by subjects. Economic needs and opportunities of subjects in the system of economic relations globalization are determined by their unity. Thus, the methodology of globalization of the transport system in the agro-industrial complex is a process through which agro-industrial transport links become more and more interconnected through new forms in the context of transport reform. The main factors and characteristics in the processes of globalization of the transport system of modern society are the establishment of certain vectors for the operation of various types of transport in the agro-industrial complex.. The old links that defined the functioning of indicators that characterize the transport sector are being integrated into a single whole. Differentiation in the analysis of transport processes requires new methodological approaches to determining the economic bases of reality

It is necessary to highlight the macro- and Mesa-level of economic agro-industrial processes in the transport problem. The macro level is determined by various external factors, so we can note the influence of economic agro-industrial processes in other countries, foreign economic expansion and other conditions. Such changes in the structure of economic agro-industrial processes require correlation with the conditions of the existing reality, precise definition of processes in the transport system of the state. Mesa-level of 
economic agro-industrial processes in the transport sector suggest the transformation of indicators of the micro-economic range and its application in the system of modern economic indicators. The micro-level is defined by view representations of criteria for establishing transport components in scalability and time measurement. Internal changes in the structure of processes in the economic agro-industrial sphere are caused by indicators of competitiveness in the transport services market.

\section{Results and discussion}

The main point of changes in this area is the allocation of various types of business to industry transport structures, for the analysis of financial and economic accounting in it, which allows rational management of income and expenses, that is, to work costeffectively. Transport has a great influence on the spatial and economic development of cities and regions. The quantity and quality of transport infrastructure affects the attractiveness and use of rural areas. An interesting emphasis on this topic is presented in modern approaches to economic activity and is determined by trade. The subjects of the exchange of labor and ideas for cash and cash for goods and services. Firms trade technology, expertise, financial capabilities, intermediate goods, administrative functions, and many other things with each other, with individuals, and with governments. All these transactions require communication, and most require the transportation of goods or people - to work, to stores, to tourist sites, and meeting places.

Thus, many farms are considering redistributing road space between different groups of road users (for example, providing more space for public transport and pedestrians) to solve the transport problem. The concept mainly depends on the priorities of agriculture at the moment, as well as on the architectural perception of time. Therefore, the problems faced by villages with regard to land use can be divided into "macroscopic" (high level) and "microscopic" (low level). The former relate to considerations such as the development of new areas, their use, and the provision of transport to promote certain types of land use. The latter are related to the reallocation of road space to meet the needs of established land use that is not covered by the existing infrastructure configuration. Nevertheless, everywhere, in any space, on the territory of any state, all of them are United by the humane goal of preserving the existing ecological biodiversity. [2, P. 5033-5035].

The variables that determine the level of development of a transport system in a given environment are accessibility and mobility. Transport affects agricultural marketing because it is the only means by which farm entities can transport their products to market. Poor transportation to rural areas has led to low productivity, low income, and a drop in the standard of living of rural residents. Strong relationships between transport, backwardness and rural areas have been identified. The greater the degree of backwardness in the transport sector in rural areas, the lower the level of transport development.. When the distance from farm to market is long and rough, that perishable crops can be destroyed and farmers may experience loss forecasts gross yield of vegetables and melons, acreage, food imports and agricultural raw materials, consumer price index for food products. It is especially important to use resources efficiently at the moment. Experience shows that the Russian cooperative consumer system consists of unique forms of management within a non-profit corporate organization [3, P. 2098-2099].

The economic mechanism of using transport systems in the structure of the agroindustrial complex is determined by economic activity and, accordingly, trade. Modern conditions actualize the search for ways to develop and improve the efficiency of large industrial associations with a high concentration of material and scientific resources that have a significant impact on a particular sector of the economy or region, and on the development of the country as a whole [4, P.291-292]. The close relationship between 
transport and trade justifies the existence of agricultural areas, since there are advantages in carrying out economic activities in their immediate vicinity. Such advantages are often referred to as" agglomeration Economics", referring to certain groups of activities that are located close to each other due to lower cost. The main reason for the agglomeration economy, especially in a world with low communication costs, is that transport costs are still significant, and proximity reduces them. The consequence of this is that anything that reduces transport costs within an urban area increases the degree of integration. Within its boundaries, the activities of subjects are easily linked to each other, and thus receive additional benefits from the agglomeration economy. In a world of many competing urban centers, those with more efficient transportation systems have an advantage. Of course, providing an efficient transport system in rural areas that ensures unhindered mobility of people and goods is not free of charge. Today, the economy faces many challenges, many of which arise from the transport system itself and are barriers to ensuring efficient transport and at the same time ensuring a good quality of life. The purpose of the study is to strengthen the presence of the mechanism in the food market and clarify the parameters of management impact based on the justification of the main provisions of regional agri-food policy [5, P. 10-11].

One of the components of economic activity is the classification of transport modes used in the agro-industrial complex. The trend in the profit of transporting agricultural products by rail is such that many entities are vitally interested in large agricultural trade. Train operations will be unprofitable in the case of the adoption of various operating costs. It is not easy to convince subjects to support demands for higher rates, at least for agricultural products. It is necessary to have profitable Railways in the interests of farming areas. Concern for the future of Railways has become so widespread that proposals are being considered to change the national transport policy and to some extent significant changes are being made to improve its efficiency. It should be understood that not all problems of national transport policy arise from financial difficulties in the operation of Railways. The attempt to replace Railways with roads has led to the fact that the resources of the former did not develop in the proper volume. Many special but important problems have arisen in connection with it. However, reasonable thinking and discussion were necessarily devoted to the relationship between various transport agencies and redefining promoting and regulating transport policy. In the formation of transport policy at all its stages, control is necessary: from the voter, the legislative process to administrative action and judicial control. The bi-directional relationship between transport and land use is developing along a certain pattern, but unexpected paradoxes may arise. For example, this is the phenomenon of "induced demand", which shows that the expansion of motorways to reduce congestion can attract the development of the transport sector. On the one hand, public transport can indirectly increase traffic congestion, since it cannot reduce the share of individual transport on the roads. On the other hand, land-use patterns in transport cannot be changed without a good reason. In countries with developed legal norms of land use in the transport sector, land use policies are implemented that do not always lead to changes and are quite limited. Special attention is given to empirical data on how land use affects travel demand. Rural "growth centers" have the longest suburbs, unlike cities. In a number of clusters of large settlements, it was found that fuel consumption per capita increases with the total population and with the share of jobs located in the center of farms. It was found that travel time increases with increasing population density, which is reflected in more or less congested train travel, which reduces the proportion of the population that lives outside the village center. The impact of land use on transport is also highly dependent on other farm-specific characteristics, which makes it difficult to develop a General transport model.

The problem of the transport situation in the system of economic activity in the agroindustrial sphere is related to the "transport bridges" in the agro-industrial complex between 
agricultural producers and markets. The markets where these products are sold are not segmented and do not fully characterize agricultural products. Transport in such conditions is a vital necessity. The relative emphasis of the transport component in relation to agricultural operations varies depending on the circumstances inherent in certain periods of agricultural development. Also important is the time period during which the efficiency of the transport system is observed and measured depending on specific agricultural and industrial areas, characterized by market needs, business cycle phases, and many other factors. The regulation and management of vehicles in the field of agricultural services was seen as being determined through negotiations and reduced operating costs. Periods of agricultural movements become voluminous and complex, and are adjusted in relation to other agricultural goals. Specific features of transport are determined by participation in the creation of agricultural products and their delivery to the consumer. The transport system is formed by the interaction of all types of transport having analyzed the data in the structure of the transport sphere, we can talk about the division into sectoral and thematic features of the transport component in the unified system of integration processes of society. Separate types of transport are distinguished based on certain characteristics of their division: railway, automobile, urban electric, road, pipeline, sea, inland water, air; as well as by thematic features and statistics of cargo and passenger transport. The defining point in the context of transport reform in agriculture is the statistics of the number of vehicles, their characteristics and use in the ways of communication. In addition, there are a number of additional signs of the globalization of the transport system in the agricultural field-these are statistics on traffic safety, labor, financial results and investment. The length of transport routes is used in the context of the need for rational use in various areas. The modern integration of economic relations in the structure of transport reform is determined by the interchangeability of different types of transport. The diversity of transport implies features in the development of agricultural systems. Agriculture is considered as a system for performing certain functions for the sale and marketing of certain types of products. Transportation of products involves special vehicles and services in these conditions. In the search for solutions to the current transport problems of agriculture in the area of tariffs and services, it is important to recognize that these problems of farmers are just special cases of more General consideration. Vehicles; railway, highway, waterway are originally intended for processing agricultural products and agricultural goods exclusively. Throughout our history, transport Agencies have been built to accommodate rural households. Many of the key problems in agriculture - for example, transportation depend heavily on a solution that applies to a particular area of existing reality. Moreover, the problem of transportation itself must be considered as part of the economic problem of our reality, which is to restore and maintain the national economy at the highest possible level of production. The Vital question is: what is the contribution of various modes of transport that contribute to a vibrant economy and healthy agriculture? The policy aimed at the future development of the transport system requires that shippers and end users correspond adequately to each other on the example of the use of fuel and raw materials. The policy adopted in relation to transport problems allows us to effectively develop the transport system in the context of a long-term period of reality.

Based on the specifics of the development of economic activities in the agro-industrial complex, we can talk about agricultural marketing. Agriculture in a broad sense means activities aimed at using natural resources for human well-being, i.e. it includes all the main types of production activities. Marketing involves a number of actions related to the movement of goods from the point of production to the point of consumption. An agricultural marketing system is described as a physical and institutional system designed to perform all activities, as well as those related to the flow of products and services, from the moment of initial agricultural production to the moment of their transfer to final 
consumers. This includes Assembly, processing, storage, transportation, processing, wholesale, retail, and export of agricultural products, as well as related support services such as providing market information, setting grades and standards, commodity trading, managing financial and price risks, and institutions involved in performing the above functions. Other economic relations theorists have explained agricultural marketing as a market function associated with the transfer of agricultural products consisting of agricultural, horticultural, and other related products from the producer to the consumer. Agricultural marketing also includes another aspect - the supply of products from rural areas to adjacent areas, as well as from rural areas to industrial areas. The form of agricultural marketing is significantly influenced by the nature of transport services. Many countries suffer from monopolistic, low-volume and expensive transport and marketing systems. Economies of scale are present in both transport and marketing operations. The share of transport charges in the final market price will vary depending on a number of factors, such as the type of product, the effectiveness of the transport and marketing sectors, and the travel distance.

The importance of an effective and modest marketing system is important for rural transport services and infrastructure for accelerated transport policy development. However, the presence of markets in itself is also a means by which effective demand for transport can be increased. The market acts as a point where goods and entities come together and thus concentrate the demand for transport. Marketing is a process that begins with making a decision about the production of a commercial agricultural product; it includes all aspects of the market structure of the system, both functional and institutional, based on technical and economic considerations and including pre-and post - harvest operations, namely: Assembly, sorting, storage, transportation and distribution of raw materials, resources and goods. Marketing is an integral part of agriculture, it encourages farmers to invest more and increase production. A simple procedure for agricultural marketing is to buy and sell agricultural products. However, in the modern period, agricultural products undergo a series of exchanges before they finally reach the consumer.

Farm products are produced over a large geographical area, and their collection is a serious problem. Sorting is problematic for agricultural products. Farmers are usually short of cash or burdened with debt, so they have to get rid of food as soon as possible. The demand and supply of agricultural products are inflexible. This means that if there is a plentiful crop, it can lead to tragedy for the farmer, and if there is a shortage of crops, the farmer cannot take advantage. The advantage goes to intermediaries. Thus, one of the goals of getting an effective marketing system is in some ways the following: 1) obtaining the maximum possible profit, 2) providing conditions for the sale of products at an incentive price, 3) reducing the price difference between the primary producer and the final consumer, 4) providing consumers with all products of farm origin at a reasonable price and within a reasonable time.

\section{Conclusions}

Transport is considered as an important factor involved in the development of the agroindustrial sector of the economy. This is the only means by which food produced on farms is moved to various homes as well as markets. Transport creates a market for agricultural products, strengthens interaction between geographical and economic regions, and opens up new directions for economic development. There are complex relationships that change both spatially and temporarily. There are three types of trails in rural areas namely: Bush trails, undeveloped rural roads, and water trails. Roads are mostly of unpaved surface, narrow width, and alignment with a low level of quality. 
The availability of vehicles is an important investment, a factor that stimulates economic growth through increased accessibility of subjects. The impact of road infrastructure on agriculture production and productivity has certain reasons. First, the agricultural sector accounts for a large share of gross domestic product. Second, poverty is concentrated in rural areas. This feature of infrastructure requires new innovations in the management structure of agricultural systems. The development of the concept of open innovation, along with the growing demands of the external environment, creates new and unique forms of management that ensure the long-term development of economic systems at both the micro and macro levels. [6, p. 503-504]. They are defined by new information technologies in the economic environment for training business entities. The relevance of the research is due to the formation and development of the educational environment in the regions in order to ensure a balanced socio-economic development of the territories. $[7, \mathrm{P}$. 44-45]. Training of business entities in the system of agro-industrial complex is considered as a process that determines all stages of development of this structure. The most effective and frequently used today in professional education: game cases, design, integrative and information technologies [8, P. 99-100].

In recent years, there have been trends in the level and structure of freight rates, which have been a big problem for agricultural products. A lot of efforts have been made to reduce this kind of rate on agricultural products. Vigorous efforts were made through a regulatory process that prevented railroads from using the "big revenue" approach, which usually means raising rates on agricultural products. Given that many Railways are in a difficult financial situation and the future of the transport system is determined by the provision and flexibility of low rates, and the solution of this problem requires further development, the Development of modern economic relations has led to the fact that the influence of tangible assets on the market value of the organization has significantly decreased and retreated to intangible assets that determine the intellectual capital of an economic entity. [9, P. 304-306]. Therefore, shippers should not lose sight of the economy and efficiency in the approach to the problem of ensuring and reducing transport costs. Shippers and consumers should insist that the transport system should be as efficient and cost-effective as possible. The modern world is becoming restless. This makes it difficult to manage the development of socio-economic systems at all levels of their hierarchy [10, P. 4916-4917]. All efforts of carriers should be limited to servicing in order to increase profits, especially profits at outdated or rebuilt facilities. Transport policy should not be based on creating a transport cartel that includes Railways or other transport routes in order to avoid necessary and desirable adjustments in tariffs, services, capitalizations, and other fixed costs.

So, the transport problem needs to be reformed, and therefore the state regulation of the strategic direction of transport development in agriculture for a certain period of time. To do this, it is necessary to create conditions for motivating subjects to use transport for agricultural transport. These features are primarily due to the customer focus on the transport and sale of certain agricultural products. Orientation to product promotion through transport marketing can be defined as the ability to have information at a certain time in a given situation. Economic analysis is the basis for the above-mentioned, taking into account the globalization of relations and relations of modern society. System analysis helps to create a concept depending on the relationship between the subject and the object (for example, the relationship to land use). Comprehensive analysis examines how products are marketed. Studies market segmentation and marketing. The transformation of economic analysis takes place at the macro-and micro-level, depending on the management tasks of the agro-industrial sphere. 


\section{References}

1. M.A. Ananiev, S.P. Burlankov, D.M. Melnikova, N.V. Sedova, International Journal of Recent Technology and Engineering, 8 (2), 4637-4642 (2019)

2. A.V. Gumerov, T.I. Ladykova, V.N. Minsabirova, R.R. Temirbulatov, L.Y. Makhotkina, M.Y. Mitrofanova, E.M. Litvinova, G.M. Kharisova, International review of management and marketing, $\mathbf{6}, 101-102$ (2016)

3. M.A. Ananiev, S.P. Burlankov, N.V. Sedova, O.M. Ananieva, International Journal of Engineering and Advanced Technology, 8(6), 2898-2901 (2019)

4. I.A. Zaraychenko, A.I. Shinkevich, M.Y. Mitrofanova, T.I. Ladykova, Y.V. Nuretdinova, G.M. Kharisova, M.A. Zhukova, Journal of Advanced Research in Law and Economics, 8(1), 291-298 (2017)

5. V.V. Andreev, G.V. Kalinina, Prawo i Więź. 8(3), 7-19 (2019)

6. M.A. Gorbunov, A.V. Fadeeva, V.B. Shirshikov, P.A. Matveev, O.V. Popova, M.Yu. Mitrofanova, Zh.Yu. Bakaeva, N.A. Mashkin, , Ekoloji, 28(107), 5033-5037 (2019)

7. O.A. Chernoyarova, A.V. Kiryakova, V.N. Ivanov, K.K.M. Batchayeva, V.V. Andreev, G.V. Kalinina, Man in India, 97(3), 43-52 (2017).

8. V.V. Andreev, E.M. Mikhailova, G.V. Kalinina, T.Ya. Silvestrova, T.N. Petrova, M.B. Kozhanova, Modern Journal of Language Teaching Methods, 7(5), 98-107 (2017)

9. E. Tkachenko, E. Rogova, N. Dmitriev, S. Bodrunov, Valuation of intellectual capital in the context of economic potential of a company, Proceedings of the European Conference on Intellectual Capital, 303-314 (2019)

10. S. Bodrunov, V.A. Plotnikov, Strategic aspects of national socio-economic development, Proceedings of the 34th International Business Information Management Association Conference (IBIMA), 4916-4922 (2019) 